\title{
IMPORTANCIA DE LA MUSICALIZACIÓN EN EL TIPO DE PERCEPCIÓN DE UNA PELÍCULA
}

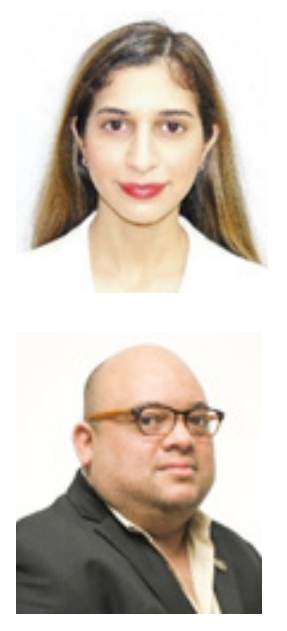

\section{Patricia Cárdenas ${ }^{\mathbf{1}}$}

Universidad Santa María La Antigua (USMA) Panamá.

patycrdenas@hotmail.com

\section{Luis Carlos Herrera ${ }^{2}$}

Universidad Santa María La Antigua (USMA) Panamá. lherrera@usma.ac.pa

DOI: $10.37594 /$ oratores.n13.411

\section{RESUMEN}

La música ha brindado diversos aportes al lenguaje cinematográfico. En la actualidad es muy difícil encontrar una película que no contenga algún acompañamiento musical. Existen diversas bibliografías que sustentan la importancia de la musicalización en las películas. Sin embargo, la gran mayoría de los estudios realizados sobre cómo influye la música en la audiencia que asiste a ver una película son de carácter cualitativo. Esta investigación demuestra el grado de correlación entre las variables: percepción de las funciones de la música en la película y percepción de la película. Se aplicó el instrumento (alfa de cronbach de 0.95) a una muestra de 500 personas que acuden al Cine Universitario de la Universidad de Panamá. Los resultados fueron puestos a prueba ante el Tau-B de Kendall. Se concluye, a partir de las pruebas estadísticas, que para la muestra de estudio existe asociación entre las variables $(\mathrm{p}<0.01)$ pero la fuerza de la correlación es moderada (Tau_b 0.466). También, que la función de la música que tiene mayor correlación es; si la música permitió darle ritmo a la película.

Palabras clave: Musicalización, cine, percepción musical, comunicación.

1 Licenciada en Ciencias de la Comunicación Social, egresada (2018) de la Escuela de Comunicación Social de la Universidad Santa María La Antigua (USMA) Panamá.

2 PhD. En Ciencias Sociales; Profesor e Investigador de la Escuela de Comunicación Social de la USMA; Miembro del Sistema Nacional de Investigación de Panamá (SNI); Investigador Asociado del CENICS. https://orcid.org/00000002-2410-7764 


\section{IMPORTANCE OF MUSICALIZATION IN TYPE PERCEPTION OF A MOVIE} ABSTRACT

Music has been an element that has provided diverse contributions to the cinematographic language. At present it is very difficult to find a film that does not contain any type of musical accompaniment. There are several bibliographies about the role that musicalization plays in movies. However, the vast majority of studies conducted on how music influences the audience that attends to watch a film are of a qualitative nature. This research demonstrates the degree of correlation between the variables: perception of the functions of the music in the film and perception of the film. The instrument (cronbach alpha of 0.95) was applied to a sample of 500 people attending the University Cinema of the University of Panama. The results were tested against Kendall's Tau-B. It is concluded, from the statistical tests, that for the study sample there is an association between the variables $(p<0.01)$ but the strength of the correlation is moderate (Tau_b 0.466). Also, that the function of music that has the highest correlation is; if the music allowed to give rhythm to the film.

Key words: Musicalization, cinema, musical perception, communication.

\section{INTRODUCCIÓN}

Desde el cine mudo, las películas tenían algún tipo de acompañamiento musical, incluía a una persona tocando el piano o incluso una orquesta completa. En 1907, el ingeniero americano Lee de Forest inventa la válvula amplificadora tríodo que consiguió que el sistema de sonido Vitaphone alcanzara los niveles exigidos para una sala de grandes dimensiones. (Gubern, 2014).

El científico Thomas Alva Edison, crea el cinematógrafo y en 1987 logra grabar una voz humana en su fonógrafo y sienta las bases, para en el futuro, sincronizar la voz e imagen. Edison y Pathé, se dedicaron a obtener la sincronización de las imágenes con discos o rodillos gramofónicos, pero estos no pasaron de ser una curiosidad experimental. (Gubern, 2014).

El cine mudo tuvo una duración de más de 35 años, y es considerado el más artístico. El cine sonoro, aunque exigía utilizar personal más especializado, favoreció formar distintos profesionales; actores, guionistas, música, montajes, diseños de imágenes y diálogos.

En 1926, el cine mudo vivía su mayor apogeo en Hollywood, y los hermanos Warner deciden sacar al mercado la novedad del cine sonoro como medida para salvarse de la bancarrota. Primero con la película muda Don Juan (1926), que fue sincronizada con música grabada de la ópera de Mozart; luego con Orgullo de raza (1927) en la que se utilizan por primera vez los ruidos y efectos sonoros; y finalmente, con El cantante de jazz (1927), convirtiéndose en la primera película que sincroniza sonido, diálogos y canciones. (Gubern, 2014). Dos años después del éxito de esa película, 
la mayoría de las empresas se pasaron al sistema sonoro, una de las uniones más importantes fue entre la Warner Bros. y la Western Electric, subsidiada por la Telephone and Telegraph (AT\&T). (Gustems, 2015). Posteriormente en lugar de utilizar un sistema de sonido en disco, el sonido fílmico se volvió estándar y así se utiliza hasta el presente. (Bordwell \& Thompson, 2003).

La implementación del sonido al cine, duplicó el número de espectadores y fue el inicio de una serie de modificaciones en la técnica y en la expresión cinematográfica. (Gubern, 2014).

La cámara tenía que ser colocada en una cabina de sonido para que el ruido de su motor no fuera captado por el micrófono, que tampoco se movía. El camarógrafo solo puede escuchar a través de sus audífonos y los actores tenían que quedarse dentro de un espacio limitado. (Bordwell \& Thompson, 2003). Los cambios en las técnicas de grabación causaron que artistas y cineastas como Chaplin y René Clair, mostraran una aversión al cine sonoro pues consideraban que esclavizaba la libertad creadora del montaje. (Gubern, 2014).

Se adoptaron soluciones como utilizar diferentes cámaras para filmar simultáneamente una escena, dentro de una cabina a prueba de sonido. La cabina de la cámara se montaba sobre ruedas para crear movimientos de cámara, o se grababa en silencio y después se le agregaba la banda sonora. (Bordwell \& Thompson, 2003). Después se utilizaron cajas más pequeñas, donde solo estaba el cuerpo de la cámara, reemplazando las cabinas. Los micrófonos montados en booms, eran alzados sobre las cabezas de los actores, para seguir la acción sin pérdida en la calidad de la grabación. (Bordwell \& Thompson, 2003)

El valor del sonido en el plano estético, permite, una mayor continuidad narrativa al eliminar los rótulos literarios que salpicaban la narración visual, las abundantes imágenes explicativas y metafóricas del lenguaje visual mudo, facilitando representar porciones de la realidad por la única presencia de su sonido y reducir un montón de planos y aumentar la longitud de estos debido a los diálogos de los actores. (Gubern, 2014)

El cine sonoro, a pesar de sus cuestionamientos, fue clave en los avances logrados; el sonido dio paso a través de los libretos o diálogos de los actores, a la posibilidad de compartir la diversidad de los problemas sociales cotidianos, eventos, historias reales y fantásticas.

\section{PRECISIONES TEÓRICAS:}

- NIVEL CONCEPTUAL

Los términos en esta investigación, deben entenderse conforme a los siguientes conceptos.

Percepción: aquella actividad mental mediante la cual determinados estímulos sensoriales 
se clasifican dentro de determinadas categorías y significados. (Lucas, García Galera, \& Ruiz San Román, 1999)

Película: toda obra audiovisual, fijada en cualquier medio o soporte, en cuya elaboración quede definida la labor de creación, producción, montaje y posproducción y que esté destinada, en primer término, a su explotación comercial en salas de cine. (EcuRed)

Música de cine: aquella que aparece sincronizada con la imagen en el transcurso de una producción audiovisual cinematográfica, sea ésta de ficción o documental, cortometraje o largometraje. (Díaz Yerro, 2011)

Banda sonora: grabación comercial de la música de una película, o el conjunto de elementos sonoros de una película. Esos son la voz, ya sea en forma de dialogo, monólogo o voz en off; los sonidos de ambiente que constituyen a la sensación de realismo; los efectos especiales sonoros y la música. (Gustems, 2015)

Ambientación musical: acto de elegir estéticamente la música apropiada a cada escena o secuencia que lo precise, considerando la unidad de conjunto y la sutileza particular en cada caso. (Beltrán Moner, 1991)

Escena: segmento en una película narrativa que tiene lugar en un tiempo y espacio o que usa planos cruzados para mostrar dos o más acciones simultáneas. (Bordwell \& Thompson, 2003)

Historia dentro de la película: los eventos que vemos y oímos, más todas aquellos que inferimos o asumimos, colocados en sus presuntas relaciones causales, orden cronológico, duración, frecuencia y situaciones espaciales. (Bordwell \& Thompson, 2003)

Ritmo cinematográfico: proporción y regularidad de sonidos percibidos, serie de tomas y movimientos dentro de ellas. Los factores rítmicos incluyen compás (o pulsación), acento (o tensión) y tiempo (o ritmo). (Bordwell \& Thompson, 2003)

\section{TIPOLOGÍAS DE LA MÚSICA EN EL CINE}

La música debe ser entendida como un lenguaje artístico que actúa como mediador de las emociones y las voluntades expresivas del compositor. Como lenguaje, es comunicativo y, por su capacidad de alterar o generar emociones, es también -si se nos permite el neologismo«comunica(c)tivo» porque actúa sobre la psique humana, calmándola o alterándola positiva o negativamente. 
Se necesita como mínimo en la música, un receptor que capte entienda e interprete aquellas emociones y que (cor) responda, emocionándose, a menudo quizás de manera expresiva e incluso mediante el gesto la danza. (Radigales, 2015, pág. 15).

Desde lo estético, es el núcleo central, el entender y hacer comprensible la música, y el hecho musical, en su máxima amplitud. (Polo, 2008, pág. 98).

La música desempeña un imprescindible papel dramático en estas películas. El elemento que aporta a las historias que el cine nos presenta, uno de los puntos más representativos de la disciplina músico cinematográfica. (Gómez, 2013, pág. 132).

Es además un elemento ornamental de simple refuerzo del discurso mostrado en pantalla y los ruidos. Por ejemplo, el genérico de una película cumple un papel contextualizador, el estilo y la instrumentación musicales nos pueden situar en una época y en una región geográfica específica. (Arranz, 2009, pág. 34).

El cine y la música se articulan entre sí, de forma tan natural. El cine crea un espacio donde escribir la música. (Porta, 2006, pág. 107).

La música del cine europeo, a diferencia de la norteamericana, estaba compuesta por una orquestación íntima y de cámara, muy delicada, con procedimientos musicales como secuencias de fondos, un ritmo marcado, regular y autónomo en relación con la imagen y el diálogo, incluso utilizando citas y fragmentos de música de concierto. (Pérez, 2014, pág. 96).

En el siguiente cuadro vemos las definiciones de tipologías de música en el cine.

\section{Cuadro 1. Tipologías de la música en el cine para L. Guerra}

\begin{tabular}{|l|l|l|}
\hline En relación con la & $\begin{array}{l}\text { Diegética: es aquella que pertenece a la diégesis, es decir, es música } \\
\text { que sucede dentro de la escena y que puede ser escuchada por los } \\
\text { personajes. }\end{array}$ \\
forma de aplicación: & $\begin{array}{l}\text { Incidental o extradiegética: que no pertenece a la diégesis y por lo tanto } \\
\text { solo es escuchada por el espectador. } \\
\text { Metadiegética: la música que es escuchada por un personaje, pero no } \\
\text { está sonando objetivamente en la escena. Es decir, es música que un } \\
\text { personaje imagina, sueña, evoca o simplemente escucha "dentro de su } \\
\text { cabeza". }\end{array}$ \\
\hline
\end{tabular}




\begin{tabular}{|l|l|}
\hline En relación con la & $\begin{array}{l}\text { Empática: es aquella música que trabaja en el mismo sentido dramático } \\
\text { de la escena, como objetivación emocional de la misma y por lo tanto } \\
\text { actitud: }\end{array}$ \\
$\begin{array}{l}\text { su fortalecimiento y confirmación. } \\
\text { Anempática: es aquella música que sigue su propia línea emocional, } \\
\text { indiferente o contraria a la línea emocional de la escena para hacer } \\
\text { contraste. }\end{array}$ \\
\hline
\end{tabular}

Fuente: (Larson Guerra, 2010, págs. 151-152, 159)

\section{Cuadro 2. Tipologías de la música en el cine para Gustems}

\begin{tabular}{|l|l|}
\hline En relación con su origen: & $\begin{array}{l}\text { Preexistente: que se compuso antes de la película. } \\
\text { Original: que se compuso específicamente para la película }\end{array}$ \\
\hline $\begin{array}{l}\text { En relación con el espectador, } \\
\text { puede ser: }\end{array}$ & $\begin{array}{l}\text { Emocional: que transmite emoción. } \\
\text { Intelectual: que transmite información. }\end{array}$ \\
\hline En relación con la vinculación: & $\begin{array}{l}\text { Integrada: donde la escena se explica por la música y } \\
\text { viceversa. } \\
\text { No integrada: donde apenas pasaría nada si la música no } \\
\text { estuviera en la escena. }\end{array}$ \\
\hline En relación con el número: & $\begin{array}{l}\text { Repetida: pues aparece más de una vez y a lo largo del } \\
\text { filme su significado es el mismo. } \\
\text { Variada: ya que no se repite y a lo largo del filme su } \\
\text { significado es el mismo. } \\
\text { Repercutida: pues se repite, aunque, durante el filme, su } \\
\text { significado no es igual, sino que va cambiando. }\end{array}$ \\
\hline
\end{tabular}

Fuente: (Gustems, 2015, págs. 111-113)

\subsection{Enfoque Teórico Adoptado}

\subsubsection{Efecto Kuleshov}

El cineasta y teórico Lev Kuleshov, es considerado como el padre de la teoría del montaje soviético. Es una ilusión mental provocada por el montaje cinematográfico, en la que el público le da un significado diferente a una misma toma dependiendo de la imagen a la que esté unida. (Sector Cine, 2017). Para demostrar este efecto, editó una breve secuencia en la que la misma toma inexpresiva del actor Ivan Mosjoukine aparecía intercalada con tres imágenes: un plato de sopa, una niña pequeña en un ataúd y una mujer echada sobre un diván. Al mostrársela a un grupo de personas, éstas aseguraron percibir que la expresión del actor cambiaba dependiendo de lo que estuviera viendo. (Sector Cine, 2017). Este efecto también puede suceder con la música de las películas. 


\subsubsection{Efecto Fisiológico}

Malamuth y Check (1980), han tratado de analizar los cambios o alteraciones producidos en los receptores a nivel fisiológico como consecuencia de la exposición a determinados mensajes televisivos. Se ha comprobado que las películas de terror provocan aceleración de los latidos del corazón y, por lo tanto, de la velocidad de circulación de la sangre. (Citado por Lucas, García Galera, \& Ruiz San Román, 1999)

Zillmann (1991) señala que al observar películas violentas se pueden dar cambios físicos, por ejemplo, el aumento de los latidos del corazón o la aceleración del ritmo respiratorio. (Citado por Lucas, García Galera, \& Ruiz San Román, 1999)

\section{MATERIALES Y MÉTODO}

El alcance de este estudio es correlacional, cuantitativa, no experimental y transeccional.

\subsection{Hipótesis}

H0 = No existe correlación entre la percepción de las funciones de la música y el tipo de percepción de las películas.

H1 = Existe correlación entre la percepción de las funciones de la música y el tipo de percepción de las películas.

En la medida de que la percepción del sujeto se interprete como mayor calidad de la música, implica una percepción positiva sobre la obra cinematográfica.

$\mathrm{X}$ (tipo de percepción sobre las funciones de la música)

Y (tipo de percepción sobre la película)

\subsection{Operacionalización de las variables}

Cuadro 3. Operacionalización de las variables

\begin{tabular}{|l|l|l|l|}
\hline Variables & \multicolumn{1}{|c|}{$\begin{array}{c}\text { Definición } \\
\text { operacional }\end{array}$} & \multicolumn{1}{c|}{ Dimensiones } & \multicolumn{1}{c|}{ Indicadores } \\
\hline & & $\begin{array}{l}\text { La ambientación a través } \\
\text { de la música }\end{array}$ & $\begin{array}{l}\text { Los elementos musicales son } \\
\text { característicos del género de la película. } \\
\text { La música ayuda a situar la acción en } \\
\text { un tiempo y lugar determinado. }\end{array}$ \\
\cline { 3 - 4 } $\begin{array}{l}\text { Percepción } \\
\text { de las } \\
\text { funciones de } \\
\text { la música. }\end{array}$ & $\begin{array}{l}\text { Concepto que se } \\
\text { hace el espectador } \\
\text { de las funciones } \\
\text { de la música en } \\
\text { base a su criterio y } \\
\text { gusto personal. }\end{array}$ & $\begin{array}{l}\text { Sobre las situaciones en } \\
\text { escena complementadas } \\
\text { por la música }\end{array}$ & $\begin{array}{l}\text { La música va acorde con las emociones } \\
\text { o acciones que se muestran en escena. }\end{array}$ \\
\cline { 3 - 4 } & & $\begin{array}{l}\text { Soporte rítmico a través } \\
\text { de la música }\end{array}$ & $\begin{array}{l}\text { La música concuerda con la duración } \\
\text { de las escenas. } \\
\text { Resalta un movimiento. }\end{array}$ \\
\hline
\end{tabular}




\begin{tabular}{|l|l|l|l|}
\hline Percepción & $\begin{array}{l}\text { Concepto que se } \\
\text { hace el espectador } \\
\text { de la película en } \\
\text { base a su criterio y } \\
\text { gusto personal. }\end{array}$ & Percepción positiva & $\begin{array}{l}\text { Hablan positivo de la película. } \\
\text { Recomiendan la película. }\end{array}$ \\
\cline { 3 - 4 } & Percepción negativa & $\begin{array}{l}\text { Hablan negativo de la película. } \\
\text { No recomiendan la película. }\end{array}$ \\
\hline
\end{tabular}

\subsection{Población y Muestra}

La población son las personas que acaban de salir de ver una película en el Cine Universitario de la Universidad de Panamá. Una sala de cine no comercial donde principalmente se proyectan películas independientes, donde el público es más exigente. Se utilizó un tamaño de la muestra de 500 personas, no probabilística por conveniencia, por lo que sus resultados son conclusiones sobre esta "n".

\subsection{Instrumento}

La validación constó por dos etapas: la primera por expertos y en la segunda; se utilizó el método de consistencia interna basado en el alfa de Cronbach, obteniendo 0.95 (Instrumento en anexo)

\subsection{Procesamiento de los datos.}

Tau b de Kendall es una prueba estadística que además de ser un coeficiente, es una prueba de hipótesis que se utiliza cuando se cruzan variables ordinales.

$$
\tau_{B}=\frac{n_{c-n_{d}}}{\sqrt{\left(n_{0}-n_{1}\right)\left(n_{0}-n_{1}\right)}}
$$

El criterio para evaluar Tau b de Kendall es el siguiente:

De 0.00 a 0.19 muy baja.

De 0.20 a 0.39 baja correlación.

De 0.40 a 0.59 moderada correlación.

De 0.60 a 0.79 buena correlación.

De 0.80 a 1.00 muy buena correlación.

\subsection{Consideraciones éticas.}

La investigación siguió los principios anotados en la Declaración de Helsinki de la Asociación Médica Mundial. (http://www.wma.net/es/30publications/10policies/b3/index.html). Además del consentimiento informado y la aprobación del Comité de Investigación de la USMA. 


\section{Resultados.}

En la muestra de 500 casos, la menor edad fue de 18 años y la mayor edad fue de 79. La edad que más asistió al cine fue de 20 años mientras que la edad media es de 28.

Tabla 3. Estadísticos Descriptivos

\begin{tabular}{|l|l|r|}
\hline \multirow{2}{*}{$\mathrm{N}$} & Válido & 500 \\
\cline { 2 - 3 } & Perdidos & 0 \\
\hline Media & 28.1040 \\
\hline Mediana & 23.0000 \\
\hline Moda & 20.00 \\
\hline Desviación & 11.92634 \\
\hline Varianza & 142.238 \\
\hline Mínimo & 17.00 \\
\hline Máximo & 79.00 \\
\hline
\end{tabular}

De 500 asistentes al cine, la mayoría fueron mujeres que representaron el $68 \%$ de los casos, mientras los hombres representan el 32\%, si tomamos en cuenta la gráfica 1; se muestra un importante grupo de mujeres jóvenes acudiendo al cine. Al ver la frecuencia por razones de género, las mujeres en su mayoría no acuden acompañadas por hombres de su misma edad.

\section{Gráfica 1. Distribución de la Muestra por Sexo en \%}

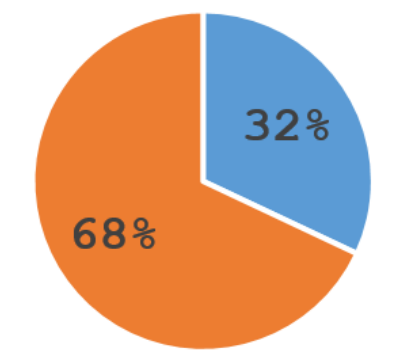

- Masculino - Eemenino

En la Tabla 5, se presenta el número de asistentes atendiendo la preferencia de película; drama en un $75 \%$ y comedia, en un $10 \%$, mientras que los de menor presencia fueron ciencia ficción con un $3 \%$ y documental en un $2 \%$. 
Tabla 5. Preferencias de Género de Película

\begin{tabular}{|l|r|}
\cline { 2 - 2 } \multicolumn{1}{c|}{} & \multicolumn{1}{c|}{ Porcentaje } \\
\hline Ciencia Ficción & 3.2 \\
\hline Drama & 74.6 \\
\hline Documental & 2.2 \\
\hline Comedia & 9.6 \\
\hline Romance & 5.8 \\
\hline Musical & 4.2 \\
\hline Terror & 0.4 \\
\hline Total & 100.0 \\
\hline
\end{tabular}

En la tabla 6, podemos ver una correlación del $63.2 \%$ cuando las funciones de la música de la película son evaluadas como muy buena y la evaluación de la película es totalmente buena, demuestra que la música en el cine es un importante factor de éxito.

\section{Tabla 6. Evaluación sobre la película vs Evaluación de las funciones de la música en la película \% del total}

\begin{tabular}{|c|l|r|r|r|r|r|}
\cline { 3 - 7 } \multicolumn{2}{c|}{} & \multicolumn{5}{|c|}{$\begin{array}{c}\text { Evaluación de las funciones de la música en la } \\
\text { película (Agrupada) }\end{array}$} \\
\cline { 3 - 8 } \multicolumn{2}{c|}{} & Muy mala & Mala & Buena & Muy buena & \multicolumn{1}{c|}{ Total } \\
\hline \multirow{3}{*}{$\begin{array}{l}\text { Evaluación } \\
\text { sobre la película }\end{array}$} & Muy Mala & $0.6 \%$ & & & $0.4 \%$ & $1.0 \%$ \\
\cline { 2 - 8 } & Mala & $0.8 \%$ & & $1.0 \%$ & $0.4 \%$ & $2.2 \%$ \\
\cline { 2 - 8 } & Buena & $0.4 \%$ & $1.8 \%$ & $3.0 \%$ & $2.4 \%$ & $7.6 \%$ \\
\cline { 2 - 8 } & Muy Buena & $0.6 \%$ & $1.6 \%$ & $14.0 \%$ & $73.0 \%$ & $89.2 \%$ \\
\hline \multicolumn{2}{|r|}{ Total } & $2.4 \%$ & $3.4 \%$ & $18.0 \%$ & $76.2 \%$ & $100.0 \%$ \\
\hline
\end{tabular}

Tabla de contingencia, donde se cruza la variable dependiente (y) nombre de la variable, y la variable independiente $(\mathrm{x})$.

Tras poner las variables bajo la prueba Tau $b$ de Kendall notamos que el valor de $p \leq 0,01$ por lo que rechazamos la hipótesis nula y aceptamos la hipótesis alterna. Esto demuestra que sí hay un grado de correlación entre las variables percepción de la evaluación de las funciones de la música en la película y la percepción de la evaluación de la película. Hay que señalar que el grado de correlación al ser de 0.43 es moderada. 
Tabla 7. Correlación - Evaluación de las funciones de la música en la película y evaluación sobre la película

\begin{tabular}{|c|c|c|c|c|}
\hline & & & \\
\hline & & & $\begin{array}{l}\text { Evaluación de } \\
\text { las funciones } \\
\text { de la música } \\
\text { en la película } \\
\text { (Agrupada) }\end{array}$ & $\begin{array}{c}\text { Evaluación sobre } \\
\text { la película }\end{array}$ \\
\hline \multirow{6}{*}{ Tau_b de Kendall } & \multirow{3}{*}{$\begin{array}{l}\text { Evaluación de } \\
\text { las funciones } \\
\text { de la música } \\
\text { en la película } \\
\text { (Agrupada) }\end{array}$} & $\begin{array}{l}\text { Coeficiente de } \\
\text { correlación }\end{array}$ & 1.000 & $.426^{* *}$ \\
\hline & & Sig. (bilateral) & & .000 \\
\hline & & $\mathrm{N}$ & 500 & 500 \\
\hline & \multirow{3}{*}{$\begin{array}{l}\text { Evaluación sobre } \\
\text { la película }\end{array}$} & $\begin{array}{l}\text { Coeficiente de } \\
\text { correlación }\end{array}$ & $.426^{* *}$ & 1.000 \\
\hline & & Sig. (bilateral) & .000 & \\
\hline & & $\mathrm{N}$ & 500 & 500 \\
\hline
\end{tabular}

**. La correlación es significativa en el nivel 0,01 (bilateral).

Fuente: elaboración propia a partir de los datos obtenidos

En el siguiente cuadro, se muestran los resultados de la prueba estadística, de los datos obtenidos a través del ritual de significancia.

\section{Cuadro 4. Explicación de los Resultados Estadísticos}

\begin{tabular}{|c|l|}
\hline 1 & $\begin{array}{l}\text { Plantear hipótesis } \\
\text { Ho: No existe correlación entre la percepción de las funciones de la música y el tipo de } \\
\text { percepción de las películas. } \\
\text { H1: Existe correlación entre la percepción de las funciones de la música y el tipo de } \\
\text { percepción de las películas. }\end{array}$ \\
\hline 2 & $\begin{array}{l}\text { Establecer nivel de significancia } \\
\text { Nivel de Significancia (alfa) } \boldsymbol{\alpha}=\mathbf{5 \%}=\mathbf{0 . 0 5}\end{array}$ \\
\hline 3 & $\begin{array}{l}\text { Seleccionar estadístico de prueba } \\
\text { Tau_b de Kendall }\end{array}$ \\
\hline
\end{tabular}




\begin{tabular}{|l|l|}
\hline 4 & $\begin{array}{l}\text { Valor de "Tau_b" calculado }=\underline{\mathbf{0 . 4 2 6}} \\
\text { Valor de } \mathbf{p}<\mathbf{0 . 0 1} \\
\text { Existe correlación entre la percepción de las funciones de la música y el tipo de percepción } \\
\text { de las películas. }\end{array}$ \\
\hline & $\begin{array}{l}\text { Interpretar el valor "Tau_b" } \\
\text { a) De } 0.00 \text { a } 0.19 \text { Muy baja } \\
\text { b) De } 0.20 \text { a } 0.39 \text { Baja correlación } \\
\text { c) De } \mathbf{0 . 4 0} \text { a } \mathbf{0 . 5 9} \text { Moderada correlación } \\
\text { d) De } 0.60 \text { a } 0.79 \text { Buena correlación } \\
\text { e) De } 0.80 \text { a } 1.00 \text { Muy buena correlación }\end{array}$ \\
\hline
\end{tabular}

Como siguiente paso, se confrontaron todas las variables de las funciones de la música en la película al Tau b de Kendall para determinar cuál tiene mayor grado de correlación con la percepción de la película.

Tabla 8. Correlación Tau_b entre tipo de percepción de la película y funciones de la música

\begin{tabular}{|c|c|c|c|c|c|c|}
\hline \\
\hline & & & Correlaciones & & & \\
\hline & & & $\begin{array}{l}\text { Evaluación sobre } \\
\text { la ambientación } \\
\text { a través de la } \\
\text { música }\end{array}$ & $\begin{array}{c}\text { Evaluación sobre las } \\
\text { situaciones en escena } \\
\text { complementadas por } \\
\text { la música }\end{array}$ & $\begin{array}{c}\text { Evaluación } \\
\text { sobre si } \\
\text { la música } \\
\text { permitió darle } \\
\text { ritmo a la } \\
\text { película }\end{array}$ & $\begin{array}{l}\text { Evaluación } \\
\text { sobre la } \\
\text { película }\end{array}$ \\
\hline \multirow{8}{*}{$\begin{array}{l}\text { Tau_b de } \\
\text { Kendall }\end{array}$} & \multirow{2}{*}{$\begin{array}{l}\text { Evaluación sobre } \\
\text { la ambientación a } \\
\text { través de la música }\end{array}$} & $\begin{array}{l}\text { Coeficiente de } \\
\text { correlación }\end{array}$ & 1.000 & $.697 * *$ & $.622 * *$ & $.440 * *$ \\
\hline & & Sig. (bilateral) & & .000 & .000 & .000 \\
\hline & \multirow{2}{*}{$\begin{array}{l}\text { Evaluación sobre } \\
\text { las situaciones } \\
\text { en escena } \\
\text { complementadas } \\
\text { por la música } \\
\end{array}$} & $\begin{array}{l}\text { Coeficiente de } \\
\text { correlación }\end{array}$ & $.697 * *$ & 1.000 & $.700 * *$ & $.459 * *$ \\
\hline & & Sig. (bilateral) & .000 & & .000 & .000 \\
\hline & \multirow{2}{*}{$\begin{array}{l}\text { Evaluación sobre si } \\
\text { la música permitió } \\
\text { darle ritmo a la } \\
\text { película }\end{array}$} & $\begin{array}{l}\text { Coeficiente de } \\
\text { correlación }\end{array}$ & $.622 * *$ & $.700 * *$ & 1.000 & $.466^{* *}$ \\
\hline & & Sig. (bilateral) & .000 & .000 & & .000 \\
\hline & \multirow{2}{*}{$\begin{array}{l}\text { Evaluación sobre la } \\
\text { película }\end{array}$} & $\begin{array}{l}\text { Coeficiente de } \\
\text { correlación }\end{array}$ & $.440 * *$ & $.459 * *$ & $.466^{* *}$ & 1.000 \\
\hline & & Sig. (bilateral) & .000 & .000 & .000 & \\
\hline
\end{tabular}

**. La correlación es significativa en el nivel 0,01 (bilateral).

Fuente: elaboración propia a partir de los datos obtenidos 


\section{Cuadro 5. Comparación de los Resultados del Tau-b de Kendall}

\begin{tabular}{|c|l|c|}
\cline { 2 - 3 } \multicolumn{1}{c|}{} & \multicolumn{1}{|c|}{ Variables } & Tau-b de kendall \\
\hline \multirow{4}{*}{ Funciones de la música } & $\begin{array}{l}\text { Evaluación sobre la ambientación a } \\
\text { través de la música }\end{array}$ & 0.440 \\
\cline { 2 - 3 } & $\begin{array}{l}\text { Evaluación sobre las situaciones en } \\
\text { escena complementadas por la música }\end{array}$ & 0.459 \\
\cline { 2 - 3 } & $\begin{array}{l}\text { Evaluación sobre si la música permitió } \\
\text { darle ritmo a la película }\end{array}$ & 0.466 \\
\hline
\end{tabular}

En el cuadro 5, bajo el Tau b de Kendall, en cada una de las variables las funciones de la música son relevantes en una película. Si comparamos todos los componentes que permiten cumplir las funciones de la música en la película, el de mayor importancia es el de asignarle ritmo a la película. Es un elemento significativo del éxito en la percepción de la película. Al comparar todas las variables, tabla 9 , presentan un $\mathrm{p}<0.01$, sin embargo, las tres más importante en orden de prioridad son: La historia, las actuaciones y la música, que da el ritmo.

\section{Agradecimientos:}

Estos resultados son posibles gracias a la Escuela de Comunicación Social de la Universidad Santa María La Antigua, y al Sistema Nacional de Investigación de Panamá (SNI). 
Tabla 9. Correlación entre la percepción de la película y todas las variables

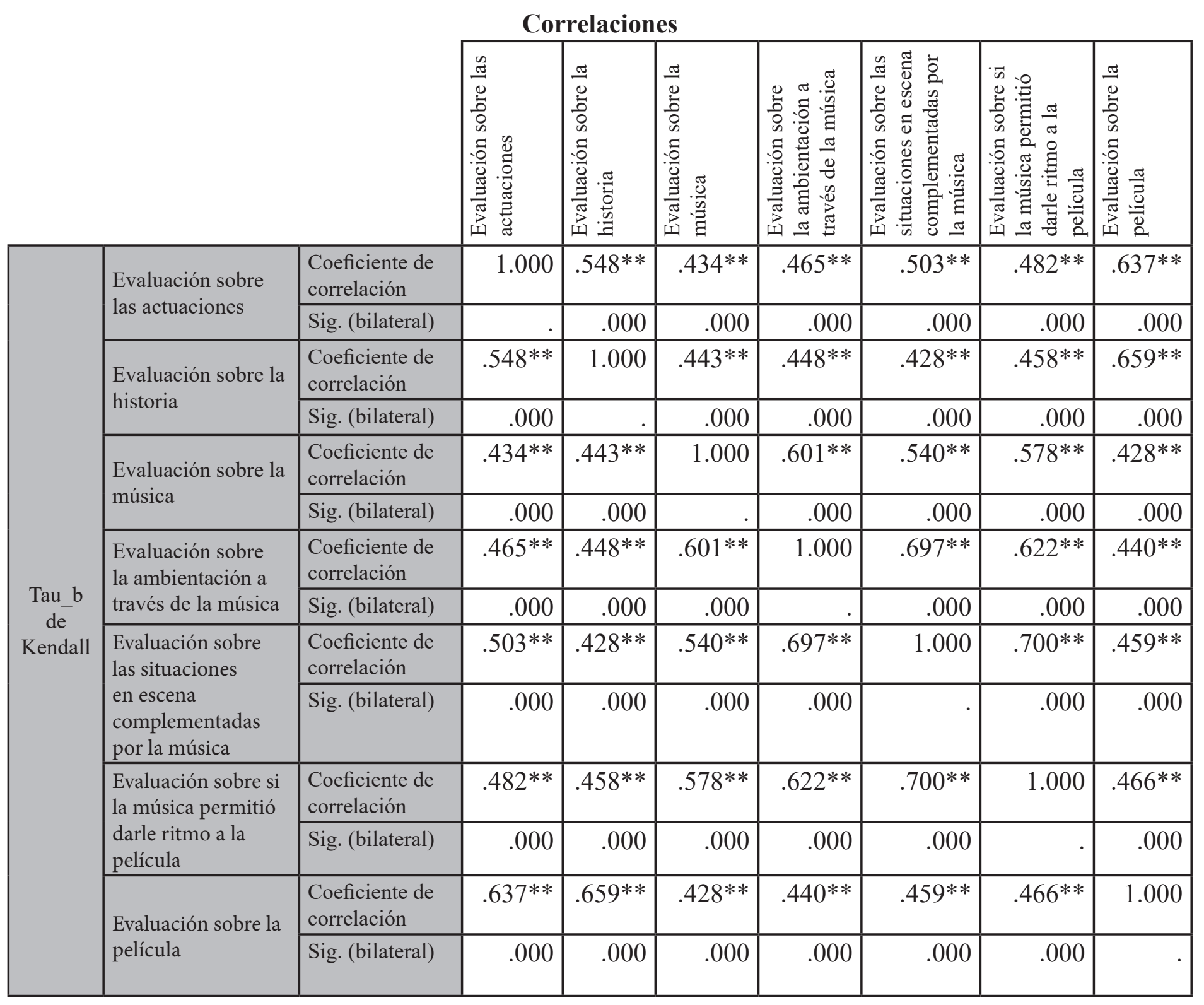

**. La correlación es significativa en el nivel 0,01 (bilateral).

Fuente: elaboración propia a partir de los datos obtenidos.

Al comparar todas las variables, presentan un $\mathrm{p}<0.01$, sin embargo, vale señalar que las tres más importante en orden de prioridad son: La historia, las actuaciones y la música, que logra darle ritmo a la película. 


\section{CONCLUSIONES Y RECOMENDACIONES}

El cine sonoro, desplaza al cine mudo a finales de los años 20, cuando se posesiona la música con distintas variantes en cada década; desde el uso del clasicismo, mezclas de instrumentos, orquestas, instrumentos electrónicos como los sintetizadores, discos compactos y la globalización del cine; la música llegó para ser un factor esencial en las películas, en sus distintos géneros.

La investigación logró confirmar la hipótesis que existe correlación entre la percepción que tiene el público ante las funciones de la música de la película, con la percepción de la película.

La evaluación de las funciones de la música, en base al grado de correlación de las variables es moderado, demuestra que la música sí incide en la evaluación de la película, pero no es el único elemento que nos va a garantizar el éxito.

Los resultados de esta investigación, confirman que la historia y las actuaciones son los elementos que más influyen en la evaluación de las personas sobre la obra cinematográfica.

Entre las recomendaciones, presentamos las siguientes:

Incluir como prioridad en la producción cinematográfica, el uso de la música, especialmente para marcar el ritmo de las escenas y diálogos con los temas musicales, es la función que mayor correlación tuvo con la evaluación positiva de la película.

Promover el uso de documentales, películas, videos, como herramientas educativas para transmitir acontecimientos de la humanidad y relatos de vida, que permitan valorar su importancia, con musicalización acorde con los públicos del cine, las Tic's a nivel global.

Estimular y promover el uso de la música de nuestros artistas nacionales, en la producción del país y a nivel internacional en las películas.

\section{REFERENCIAS BIBLIOGRÁFICAS}

- Arranz, E. (2009). Nueva concepción del sonido audiovisual y los efectos expresivos en el cine contemporáneo. Madrid: Universidad Complutense de Madrid.

- Beltrán Moner, R. (1991). Ambientación musical. Selección, montaje y sonorización. Madrid: Instituto Oficial de Radio Televisión Española.

- Bordwell, D., \& Thompson, K. (2003). Arte Cinematográfico. México D.F.: McGraw- 
Hill Interamericana.

- Díaz Yerro, G. (2011). El análisis de la música cinematográfica como modelo para la propia creación musical en el entorno audiovisual. Las Palmas de Gran Canaria : Universidad de Las Palmas de Gran Canaria .

- EcuRed. (s.f.). EcuRed. Obtenido de EcuRed: https://www.ecured.cu/Pel\%C3\%ADcula

- Gaona Pallares, E., \& Abadía Guzmán, J. (2015). Crecimiento de la musicalización del cine en Panamá. Panamá: Universidad de Panamá.

- Gubern, R. (2014). Historia del cine. Barcelona: Editorial Anagrama.

- Gustems, J. (2015). Música y sonido en los audiovisuales. Barcelona: Publicacions i Edicions de la Universitat de Barcelona.

- Heredia, F., Garrido, D., \& Carnicer, J. (2014). SOUND CHARACTERISTICS ON FILM TRAILERS. Vivat Academia, 17(129), 1-9.

- Larson Guerra, S. (2010). Pensar el sonido. México D.F.: Universidad Nacional Autònoma de Mèxico.

- Lucas, A. M., García Galera, C., \& Ruiz San Román, J. A. (1999). Sociologia de la Comunicación. Madrid: Editorial Trotta.

- Morante, L. (2008). The overlapping of sound and the narrative structure of the audiovisual message. Revista Latina de Comunicación Social(63), 400-408.

- Pérez, H. (2014). Música de Cine: John Williams \& Steven Spielberg. Santa Fe: UNL.

- Polo, M. (2008). La Estética de la Música. Barcelona: UOC.

- Porta, A. (2006). Cine, música y aprendizaje significativo. Comunicar, 106-113.

- Radigales, J. (2015). La música en el cine. Barcelona: UOC.

- Sector Cine. (13 de 9 de 2017). Sector Cine. Obtenido de Sector Cine: https://sectorcine. com/noticias/nota/el-efecto-kuleshov/

- Stewart, H. (28 de Septiembre de 2013). BBC. Obtenido de BBC: http://www.bbc.com/ mundo/noticias/2013/09/130921_cine_musica_manipulacion_finde

- University of Oslo. (7 de Mayo de 2015). ScienceDaily. Recuperado el 15 de Enero de 2017, de ScienceDaily: https://www.sciencedaily.com/releases/2015/05/150507082439. htm

- Vigo Dávila, A. A., \& De La Flor Arbulú, M. (2014). Influencia De La Banda Sonora En La Evaluación De Personajes De Una Película. Lima: Pontificia Universidad Católica del Perú.

- Zuazu, M., \& Canon, R. (2014). Las músicas de Betty, la fea. Revista de Música Latinoamericana, 1-24. 